\title{
PRAKTIKALITAS DAN KEEFEKTIFAN MODUL GEOMETRI ANALITIK RUANG BERBASIS KONSTRUKTIVISME
}

\section{PRACTICALITY AND EFFECTIVENESS OF GEOMETRY ANALYSIS MODULE BASED ON CONSTRUCTIVITY}

\author{
${ }^{1}$ Nina Agustyaningrum, ${ }^{2}$ Yesi Gusmania \\ ${ }^{1,2}$ Program Studi Pendidikan Matematika, Fakultas Keguruan dan Ilmu Pendidikan, \\ Universitas Riau Kepulauan, Indonesia \\ Email::Iagustyaningrum@gmail.com
}

\begin{abstract}
Abstrak
Tujuan penelitian ini adalah untuk mengembangkan modul geometri analitik ruang berbasis konstruktivisme yang praktis dan efektif. Metode penelitian ini menggunakan model pengembangan proseduralInstruksional Development Institute (IDI) yang terdiri dari 3 tahap yaitu tahap penentuan (define), tahap pengembangan (develop), dan tahap evaluasi (evaluate).Penelitian ini dibatasi pada tahap develop yaitu praktikalitas modul dan tahap evaluate yaitu keefektifan modul. Sedangangkan tahap define telah dilakukan pada penelitian terdahulu. Instrument yang digunakan adalah angket untuk praktikalitas dan tes untuk melihat keefektifan.Subjek penelitian adalah 25 orang mahasiswa program studi pendidikan matematika di Universitas Riau Kepulauan.Data hasil angket dianalisis dengan menghitung persentase pencapaian pada setiap aspek, sedangkan data tes dianalisis dengan menghitung persentase jumlah mahasiswa yang mendapat nilai lebih dari 68. Hasil analisis data angket praktikalitas didapat rata-rata persentase pencapaian aspek secara keseluruhan adalah $81,9 \%$ termasuk pada kategori Baik sedangkan hasil analisis skor tes diperoleh rata-rata skor tes adalah 79,5 dengan persentase jumlah mahasiswa yang mendapat nilai lebih dari 68 adalah 88\%. Dari hasil tersebut dapat disimpulkan bahwa modul telah praktis digunakan dan efektif dalam menunjang kompetensi mahasiswa pada mata kuliah geometri analitik ruang.
\end{abstract}

Kata Kunci : Geometri analitik ruang, konstruktivisme, Modul, Praktikalitas

\section{Abstract}

This research purposed to develop a practical and effective spaced analytic geometry module based on constructivism approach. The research method uses procedural development model of Instructional Development Institute (IDI) that consist of 3 stages namely define, development, and evaluation stage. This research was focused to develop stage (i.e. the module practicality) and evaluate stage (i.e. the module effectiveness). While the define stage has been done in previous research. The instrument used was a questionnaire for practicality and tests for effectiveness. The subjects were 25 students of mathematics education program at Universitas Riau Kepulauan. Questionnaire data were analyzed by calculating percentage of achievement in every aspect, while test data were analyzed by calculating percentage of total students who got score more than 68. The result of questionnaire data analysis obtained the average percentage of achievement aspect as a whole was $81.9 \%$ included in Good category while the test score analysis results obtained the average test score was 79.5 with the percentage of the number of students who score more than 68 was 88\%. From these results it can be concluded that the module has been practically used and effective in supporting students' competence in space analytic geometry courses.

Keywords : constructivism,module, space analytic geometry 


\section{PENDAHULUAN}

Geometri analitik ruang menjadi salah satu mata kuliah wajib bagi mahasiswa utamanya pada program studi matematika dan pendidikan matematika.Menurut (Kosa \& Karakus, 2010) geometri dapat dianggap sebagai asal mula visualisasi dalam matematika.Mempelajari geometri analitik ruang menjadi suatu hal yang penting bagi mahasiswa tersebut karena materi dalam mata kuliah ini menjadi dasar dalam mempelajari materi kalkulus pada umumnya (Sukirman, 2009: ii). Oleh karena itu dengan menguasai mata kuliah ini dengan baik akan sangat membantu mempelajari materi kalkulus terutama yang berkaitan dengan menggambar grafik atau kurva dari suatu persamaan.

Ketersediaan buku-buku referensi dan bahan ajar geometri analitik ruang sebagai sarana bagi mahasiswa dalam belajar tentulah menjadi hal yang penting.Namun berdasarkan pengalaman peneliti dalam mengampu mata kuliah geometri analitik ruang di Universitas Riau Kepulauan selama dua tahun terakhir, ketersediaan referensi yang memadai menjadi suatu kendala tersendiri yang belum mampu untuk diatasi.Referensi utama yang digunakan adalah buku cetakan lama (cetakan tahun 1986 dan 1994) yang pada beberapa bagian sudah tidak jelas ketikan dan gambarnya. Sehingga sangat perlu dikembangkan suatu bahan ajar yang dapat memfasilitasi mahasiswa agar lebih mudah dalam mempelajari geometri analitik ruang.

Haviger \& Vojkůvková(2014) menyatakan bahwa dalam mempelajari geometri akan sangat sesuai apabila digolongkan atau memperhatikan level kemampuan berpikir dari peserta didik. Oleh karena itu harus dicari suatu pendekatan yang sesuai dengan materi dan tingkat kemampuan berpikir mahasiswa.Konstruktivisme adalah salah satu filsafat pengetahuan yang menekankan bahwa pengetahuan kita adalah konstruksi (bentukan) kita sendiri.Von Glasenveld menegaskan bahwa pengetahuan bukanlah suati tiruan dari kenyataan (Suparno, 1997: 18). Proses pembelajaran yang terjadi menurut pandangan konstruktivisme menekankan pada kualitas keaktifan pebelajar (mahasiswa) dalam menginterpretasikan dan membangun pengetahuannya. Dengan mengonstruk pemahaman menjadikan konsep materi pelajaran tertanam lebih kuat di benak mahasiswa karena yang mereka lakukan adalah membangun pemahaman bukan sekedar menghafal materi.

Oleh karena itu dalam penelitian terdahulu, peneliti telah mengembangakan modul geometri analitik ruang berbasis konstruktivisme yang telah diuji kevalidannya oleh 3 validator. Hasil penilaian kualitas modul dari 3 validator yang meliputi aspek kelayakan isi, penyajian, dan kebahasaan berturut-turut diperoleh persentase pencapaian skor adalah $86,11 \%, 87,04 \%$, dan 89,29\%. Untuk keseluruhan kelayakan modul persentase pencapaian 
skornya adalah $87,48 \%$ dengan kategori sangat baik. Dengan demikian pada penelitian terdahulu telah dihasilkan modul yang valid.

Penelitian ini merupakan kelanjutan dari penelitian terdahulu yang bertujuan untuk melihat praktikalitas (kemudahan) penggunaan modul dan bagaimana keefektifan modul dalam menunjang kompetensi mahasiswa pada mata kuliah geometri analitik ruang.Dengan demikian, akan didapat informasi yang jelas seberapa praktis dan efektif modul dapat digunakan sebagai alternatif referensi dalam pembelajaran geometri analitik ruang.

\section{METODOLOGI}

\section{Jenis dan Prosedur Penelitian}

Penelitian ini merupakan jenis penelitian pengembangan (research and development). Model pengembanganyang digunakan mengacu pada model proseduralInstruksional Development Institute (IDI) yang terdiri dari 3 tahap yaitu tahap penentuan (define) dengan menganalisis kebutuhan, tahap pengembangan (develop), dan tahap evaluasi (evaluate). Tahap define dan tahap develop (langkah validasi) telah dilaksanakan pada penelitian terdahulu. Sehingga dalam penelitian ini fokus pada tahap develop (langkah praktikalitas) dan tahap evaluate. Langkah-langkah untuk melaksanakan kedua tahap tersebut sebagai berikut.

1. Tahap Praktikalitas

Praktikalitas merupakan tingkat keterpakaian atau kemudahan bahan ajar untuk digunakan oleh mahasiswa.Aspek praktikalitas yang diukur adalah aspek kemudahan penggunaan dan aspek penyajian.Untuk aspek kemudahan penggunaan meliputi kemudahan memahami materi dan Bahasa yang digunakan dalam modul.Sedangkan aspek penyajian fokus pada tampilan modul.Untuk mendapatkan tingkat praktikalitas, modul yang telah valid diujicobakan kepada 25 orang mahasiswa program studi pendidikan matematika di FKIP Universitas Riau Kepulauan.Bahan ajar dikatakan praktis jika sudah hasil penilaian praktikalitas telah mencapai kategori Baik sesuai dengan kriteria yang telah ditetapkan.Jika hasil belum praktis, maka akan dilakukan perbaikan sesuai dengan saran dari responden.

\section{Tahap Evalute}

Pada tahap penilaian, kegiatan dipusatkan untuk mengevaluasi apakah prototipe (versi ujicoba) dapat digunakan sesuai dengan harapan dan efektif untuk meningkatkan kompetensi mahasiswa dalam hal ini hasil belajar mahasiswa pada mata kuliah geomteri 
analitik ruang. Hasil belajar mahasiswa diperoleh melalui tes. Kemudian, berdasarkan pertimbangan bahwa kategori nilai B di program studi pendidikan matematika Unrika berada pada range 68-79,99, maka peneliti menentukan bahwa bahan ajar yang dikembangkan dikatakan efektif apabila lebih dari 70\% mahasiswa mendapatkan nilai $\geq$ 68.

\section{Instrumen Penelitian}

Instrumen yang digunakan dalam penelitian ini berupa angket mahasiswa untuk mendapatkan data praktikalitas dan tes hasil belajar geometri analitik ruang sesuai dengan materi ujicoba. Angket praktikalitas terdiri dari 16 item pernyataan dengan dengan 10 item untuk mengukur aspek kemudahan penggunaan dan 6 item untuk mengukur aspek penyajian. Sedangkan instrumen tes berbentuk tes uraian yang terdiri dari 3 soal.

\section{Teknik Analisis Data}

Hasil skor angket disajikan dalam bentuk tabel kemudian dicari persentase skor pada tiap aspek dengan menggunakan rumus:

$$
p=\frac{\sum \text { skor per aspek }}{\text { skormaks per aspek } \times \text { jumlah responden }} \times 100 \% \text {, dengan } P: \text { Persentase }
$$

Selanjutnya rerata yang diperoleh diinterpretasikan sesuai dengan kriteria yang ditetapkan seperti pada tabel 1 berikut.

Tabel 1. Kriteria Kepraktisan Modul

\begin{tabular}{cl}
\hline Rentang Skor & \multicolumn{1}{c}{ Predikat } \\
\hline Mi $+1,8$ Sbi $<\bar{X}$ & Sangat Baik \\
Mi $+0,6$ Sbi $<\bar{X} \leq \mathrm{Mi}+1,8$ Sbi & Baik \\
Mi $-0,6$ Sbi $<\bar{X} \leq \mathrm{Mi}+0,6$ Sbi & Cukup Baik \\
Mi $-1,8$ Sbi $<\bar{X} \leq \mathrm{Mi}-0,6$ Sbi & Kurang \\
$\bar{X} \leq \mathrm{Mi}-1,8$ Sbi & Sangat Kurang \\
\hline
\end{tabular}

Sumber: Diadaptasi dari Widoyoko (2014: 238)

Keterangan:

$\bar{X}$

Skor maksimal ideal

$=$ Nilai Rata-rata

Skor minimal ideal

$=$ jumlah indikator $\mathrm{x}$ skor tertinggi

$=$ jumlah indikator $\mathrm{x}$ skor terendah

Mi (mean ideal)

$=\frac{1}{2}$ (skor maks ideal + skor min ideal $)$

Sbi (simpangan baku ideal) $=\frac{1}{6}$ (skor maks ideal - skor min ideal)

Untuk hasil tes, diberikan nilai sesuai dengan panduan penilaian yang telah ditetapkan lalu dihitung nilai rata-rata yang diperoleh dan persentase jumlah mahasiswa yang mendapat nilai lebih dari 68 . 


\section{HASIL PENELITIAN DAN PEMBAHASAN}

Untuk melihat praktikalitas modul, telah dilakukan uji coba pada 25 mahasiswa Pendidikan Matematika, FKIP Universitas Riau Kepulauan angkatan 2015.Dalam penelitian ini modul yang sudah dikembangkan diujicobakan pada mahasiswa program studi pendidikan matematika semester V Universitas Riau Kepulauan tahun ajaran 2017/2018.Uji coba produk dilaksanakan di bulan September 2017 pada pokok bahasan sistem koordinat ruang.Selanjutnya mahasiswa diberikan angket untuk mengetahui kepraktisan modul dan diberikan tes untuk mengetahui keefektifan modul.

Sebelum menghitung persentase skor praktikalitas, akan dihitung terlebih dahulu kriteria praktikalitas sesuai dengan rumus pada tabel 1.

Jumlah item pernyataan $\quad=16$ item

Skor maks ideal $\quad=4 \times 16=64$

Skor min ideal $\quad=1 \times 16=16$

Mi

$=\frac{1}{2}(100+25)=62,5$

Sbi

$=\frac{1}{6}(100-25)=12,5$

Tabel 2. Kriteria Kategori Kepraktisan Modul

\begin{tabular}{cc}
\hline Rentang Skor & Predikat \\
\hline $54,4<\bar{X}$ & Sangat Baik \\
$44,8<\bar{X} \leq 54,4$ & Baik \\
$33,2<\bar{X} \leq 44,8$ & Cukup Baik \\
$25,6<\bar{X} \leq 33,2$ & Kurang \\
$\bar{X} \leq 25,6$ & Sangat Kurang \\
\hline
\end{tabular}

Selanjutnya hasil perhitungan skor angket praktikalitas disajikan pada tabel 3 berikut.

Tabel 3. Deskripsi Data Skor Angket Kepraktisan Modul

\begin{tabular}{lc}
\hline \multicolumn{1}{c}{ Deskripsi Data } & Skor \\
\hline Rata-rata & 52,44 \\
Simpangan Baku & 4,36 \\
Varians & 19,01 \\
Skor tertinggi & 59 \\
Skor terendah & 44
\end{tabular}




\begin{tabular}{ll} 
Skor maximum ideal & 64 \\
Skor minimum ideal & 16 \\
Jumlah responden & 25 \\
\hline
\end{tabular}

Berdasarkan data pada tabel 3, rata-rata skor angket praktikalitas adalah 52,44 sehingga termasuk pada kategori baik. Jika dihitung persentasenya maka diperoleh pencapaian praktikalitas sebesar $\frac{52,44}{64} \times 100 \%=81,9 \%$. Skor simpangan baku sebesar 4,36 menunjukkan bahwa para responden rata-rata memberikan nilai yang tidak jauh berbeda dari nilai rata-rata. Hal ini berarti rata-rata keseluruhan responden memberikan respon yang baik terhadap penggunaan modul.Sementara itu, untuk hasil persentase pencapaian untuk setiap aspeknya adalah sebagai berikut.

Tabel 4. Hasil Uji Praktikalitas untuk Setiap Aspek

\begin{tabular}{lrcc}
\hline No. & Aspek & Persentase & Kategori \\
\hline 1. & Kemudahan & $82,9 \%$ & Baik \\
& penggunaan & & \\
2. & Penyajian & $80,33 \%$ & Baik \\
\hline
\end{tabular}

Berdasarkan hasil pada tabel 4, terlihat bahwa persentase pencapaian praktikalitas untuk setiap aspek sudah berada pada kategori baik.Dari hasil uji praktikalitas yang diperoleh dapat disimpulkan bahwa modul telah praktis untuk digunakan dalam perkuliahan.

Namun demikian, untuk mendapatkan informasi lebih mendalam, pada angket juga diberikan ruang untuk menyampaikan komentar/kritik/saran. Hal ini dimaksudkan agar mahasiswa lebih leluasa jika ingin menyampaikan pendapatnya. Sebagian besar mahasiswa memberikan komentar positif yaitu merasa sangat terbantu dengan adanya modul ini. Sementara itu berdasarkan saran yang diperoleh dari mahasiswa, ada beberapa revisi yang dilakukan yaitu memperbaiki penulisan, memperbanyak contoh-contoh soal yang bervariasi, serta menambah ruang interaksi dalam penyajian materi dengan meninggalkan blank space dan menambah kolom tugas untuk dilengkapi mahasiswa. Pemberian blank space dan kolom tugas dimaksudkan agar melatih mahasiswa untuk belajar lebih mandiri dalam membangun konsep pemahaman materi sesuai dengan prinsip konstruktivisme. Dengan demikian mahasiswa menjadi lebih aktif dalam pembelajaran.

Setelah didapat modul yang praktis langkah berikutnya adalah melihat keefektifan modul yang dikembangkan.Setelah mahasiswa mengikuti perkuliahan dengan menggunakan 
modul, mahasiswa diberikan tes untuk melihat keefektifan penggunaan modul. Deskripsi data hasil tes yang diperoleh disajikan pada tabel 4 berikut.

Tabel 5. Deskripsi Data Skor Tes Hasil Belajar

\begin{tabular}{lc}
\hline \multicolumn{1}{c}{ Deskripsi Data } & Skor \\
& \\
\hline Rata-rata & 79,50 \\
Simpangan Baku & 14,65 \\
Varians & 214,58 \\
Skor tertinggi & 100 \\
Skor terendah & 30 \\
Skor maximum ideal & 100 \\
Skor minimum ideal & 0 \\
Jumlah responden & 25 \\
\hline
\end{tabular}

Berdasarkan tabel 5 di atas, terlihat bahwa rata-rata skor tes sebesar 79,50 dengan simpangan baku 14,65. Untuk distribusi frekuensi hasil tes disajikan pada tabel 6 berikut.

Tabel 6. Distribusi Frekuensi Skor Tes Hasil Belajar

\begin{tabular}{ccc}
\hline Interval Skor & Frekuensi & Persentase \\
\hline $90-100$ & 7 & $28 \%$ \\
$80-89,99$ & 7 & $28 \%$ \\
$70-79,99$ & 8 & $32 \%$ \\
$60-69,99$ & 1 & $4 \%$ \\
$50-59,99$ & 1 & $4 \%$ \\
$30-49,99$ & 1 & $4 \%$ \\
Jumlah & 25 & $100 \%$ \\
\hline
\end{tabular}

Pada tabel distribusi frekuensi terlihat bahwa hanya 3 dari 25 mahasiswa saja yang masih memperoleh nilai di bawah 70 (data asli pada interval 60 - 69,99 nilainya di bawah 68). Sehingga persentase jumlah mahasiswa yang mendapat skor tes lebih dari 68 sebesar $88 \%$. Berdasarkan kriteria yang telah ditetapkan yaitu lebih dari $70 \%$ mahasiswa memperoleh skor tes lebih dari 68, maka dapat disimpulkan bahwa modul yang dikembangkan efektif dalam menunjang kompetensi mahasiswa pada mata kuliah geometri analitik ruang.

Hasil penelitian ini sesuai dengan yang dikemukakan oleh Gusmania \& Tubagus (2015) yaitu pengembangan bahan ajar akan berdampak positif dalam meningkatkan kompetensi mahasiswa. 


\section{KESIMPULAN DAN SARAN}

\section{Kesimpulan}

Dari penelitian yang telah dilaksanakan, dapat disimpulkan bahwa:

1. Modul geometri analitik ruang berbasis pendekatan konstruktivisme yang dikembangkan praktis untuk digunakan dengan persentase pencapaian kepraktisan 81,9\% (kategori baik).

2. Modul geometri analitik ruang berbasis konstruktivisme yang dihasilkan efektif dalam menunjang kompetensi mahasiswa pada mata kuliah geometri analitik ruang dengan perolehan skor rata-rata hasil tes 79,50. Jumlah mahasiswa yang memperoleh nilai lebih dari 68 sebanyak 22 dari 25 responden mahasiswa atau sebesar $88 \%$ mahasiswa.

\section{Saran}

Berdasarkan perolehan hasil penelitian, maka peneliti dapat menyampaikan beberapa saran sebagai berikut:

1. Bagi dosen pengampu mata geometri analitik ruang modul ini dapat dijadikan sebagai salah satu referensi tambahan sumber belajar.

2. Bagi peneliti lain dapat mencoba mengembangkan bahan ajar serupa pada materi yang berbeda sesuai dengan kebutuhan.

3. Modul sebaiknya juga diujicobakan pada kelas lain atau universitas lain untuk mengetahui dampak efektifitasnya secara lebih luas.

4. Bagi peneliti agar membuat modul lanjutan untuk seluruh materi geometri analitik ruang yang belum tercakup dalam modul.

5. Mahasiswa dapat menggunakan modul ini sebagai alternatif bahan pembelajaran pada perkuliahan geometri analitik ruang.

\section{REFERENSI}

Gusmania, Y. dan T. P. (2010). Pengembangan Modul Geometri Analitik Bidang Berbasis Contextual Teaching Learning (CTL) untuk Meningkatkan Kompetensi Mahasiswa Universitas Riau Kepulauan (UNRIKA). JurnalDimensi, 4(3), 1-11. Retrieved from http://journal.unrika.ac.id/index.php/jurnaldms/article/view/44/42

Haviger, J. \& Vojkůvková, I. (2014). The van Hiele geometry thinking levels: gender and school type differences. ProcediaSocial and Behavioral Sciences, 112 ( 2014 ) 977 981. Retrieved from http://ac.els-cdn.com/S1877042814012749/1-s2.0S1877042814012749-main.pdf?_tid=2056c468-96be-11e7-a25f00000aacb35e\&acdnat=1505113079_430f2c004b3a64812c2684c4aecd8ee6 jiri haviger

Kosa, T. \& Karakus, F. (2010). Using dynamic geometry software Cabri 3D for teaching analytic geometry. Procedia Social and Behavioral Science, 2 (2010) 1385-1389. Retrieved from http://ac.els-cdn.com/S1877042810002442/1-s2.0-S1877042810002442- 
main.pdf? tid=612eb92e-96bd-11e7-bb75-

$\underline{\text { 00000aab0f01\&acdnat }=1505112758 \_5 a 65313 \mathrm{c} 05 \mathrm{a} 8577768850 \mathrm{a} 8267 \mathrm{f} 15 \mathrm{ec} 6}$

Sukirman. (2009). Geometri Analitik Bidang dan Ruang. Jakarta: Penerbit Universitas Terbuka.

Suparno, Paul. 1997. Filsafat Konstruktivisme dalam Pendidikan. Yogyakarta: Kanisius.

Widoyoko, E.P. (2014). Evaluasi program pembelajaran: panduan praktis bagi pendidik dan calon pendidik. Yogyakarta: Pustaka Pelajar 